\title{
Qualitative and Quantitative Analysis of Various Classes of Alcohol Dehydrogenase in Structures of Rat Skin
}

\author{
Rolf Handschin, I. Piotr Maly, Valérie Crotet, Mireille Toranelli and Dieter Sasse \\ Institute of Anatomy, University of Basel, Switzerland
}

Received for publication November 6, 1997

The three classes of alcohol dehydrogenase $(A D H)$ in the rat which have been described at the protein level were subjected to qualitative and quantitative analysis by histochemical and microelectrophoretic means. Enzyme activity was studied in the epidermis, sebaceous glands, hair roots, stratum papillare, stratum reticulare and panniculus carnosus of the rat skin. Total ADH activity was histochemically demonstrable in all these structures. After electrophoretic separation of microdissected samples by a newly developed ultrathin-layer gel electro- phoresis technique, no class I ADH activity was found in any of the above-mentioned structures, whereas class III ADH activity was ubiquitously detectable, although only at a faint level. Class IV ADH however, showed high activity in the epidermis and the sebaceous glands. Maximum activity could be attributed to the fibroblasts of the stratum papillare. The metabolic role of class IV ADH in the skin is discussed with respect to retinoic acid synthesis and the degradation of lipid peroxidation products.

Key words: Alcohol dehydrogenase, Isoforms, Skin, Rat

\section{Introduction}

The ADH enzyme family has been the subject of an extensive literature $[11,13,14]$. The dimeric, medium-chain ADHs, which occur in vertebrates, have so far been subdivided into classes I to VI [13]. In the rat, three of them have been detected at the protein level, namely classes I, III and IV. They were formerly designated ADH-3, ADH-2 and ADH-1 [15].

Class I ADH, (the former ADH-3), is the classical ethanol-degrading enzyme with a low $\mathrm{Km}$ for ethylalcohol, homologous to human class I ADH [20, 25]. It occurs mainly in the liver and is responsible for $96 \%$ of the total ethanol metabolism at physiological ethanol concentrations [1]. Class III ADH, (the former ADH-2), is the ubiquitous glutathione-dependent formaldehyde dehydrogenase [18]. It contributes to basic metabolic defense mechanisms by metabolizing endogenously produced formaldehyde [12]. Class IV ADH, (the former ADH-1), is found in epithelial tissues [1]. Its presence in the mucosa

Essential parts of this study will be presented as an Inaugural Dissertation to the Medical Faculty of the University of Basel by R. Handschin.

Correspondence to: Prof. Dr. D. Sasse, Anatomisches Institut, Pestalozzistr. 20, CH-4056 Basel, Switzerland. of the upper digestive tract enables the enzyme to act in the firstpass metabolism of ingested ethanol [16]. Furthermore, it is thought to protect against products of lipid peroxidation, and is also considered to play a role in retinoic acid synthesis [2].

In order to get a quantitive analysis of enzyme activity in defined structures of the skin, an appropriate method had to be chosen. To achieve this goal a combination of histochemical and microbiochemical methods was necessary.

Enzyme histochemical techniques provide qualitative insight into the occurrence and localization of many enzyme activities in tissue sections. Among other tissues the skin of different species was also subjected to earlier histochemical examination $[8,26]$. However, the techniques used in these studies must be regarded with caution, and the former findings on $\mathrm{ADH}$ distribution in the skin urgently deserve a reevaluation. Furthermore, in order to achieve a resolution of enzyme classes or isozymes in microscopically defined areas of the tissue, microdissection had to be combined with electrophoresis. For the electrophoretic separation of samples in the nanogram range, a miniaturized electrophoretic system was developed [22]. Using the so-called "ultrathin-layer zone electrophoresis", the local distribution of lactate dehydrogenase isozymes was at first investigated in the liver [22] and in corneal and conjunctival epithelia [19], 
and that of malate dehydrogenase isozymes in the liver [23]. To separate the different ADH classes and isozymes, the ultrathin-layer zone electrophoresis had to be modified [24]. Now this method represents a powerful tool for investigating small, defined structures for the activity of the single ADH classes.

Since ADH has been linked up to physiological processes relevant for the skin, such as retinol metabolism and the degradation of lipid peroxidation products [2], it was the aim of this study to identify and to localize the ADH classes in rat skin. Therefore the distribution of total ADH activity in rat skin was at first demonstrated histochemically; later, structures showing high reactivity (epidermis, sebaceous glands, hair roots, connective tissue and subcutanous muscle) were isolated by the microdissection of lyophilized sections and analyzed in a microelectrophoretic system in order to determine the class and relative quantity of ADH present in the defined skin components.

\section{Materials and Methods}

\section{Animals and tissue sampling}

Twelve week-old Wistar rats were obtained from Madörin (Füllinsdorf, Switzerland). The rats were kept at a constant room temperature of $21^{\circ} \mathrm{C}$ and a $12-\mathrm{hr}$ light/dark cycle (7a.m.-7p.m.). The animals had free access to water and to Kliba maintenance diet. They were sacrified by a blow on the head followed by decapitation and exsanguination between 10-11a.m. The liver, the stomach and a shaved skin strip from the back were removed; liver and stomach were cut into small tissue blocks with a razor blade. The skin strips were embedded in Tissue Freezing Medium (Jung, Germany). All samples were rapidly frozen in liquid $\mathrm{N}_{2}$ and stored in airtight tubes at $-80^{\circ} \mathrm{C}$ until required. ADH activity was determined by means of microelectrophoresis in homogenates and in microdissected tissue samples, and by the techniques of staining histochemistry.

\section{Homogenates}

For the preparation of homogenates, liver and stomach samples were weighed and immediately homogenized in $19 \mathrm{vol}$ (liver and stomach) or $9 \mathrm{vol}$ (skin) of ice cold $20 \mathrm{mM}$ Tris-SO ${ }_{4}, \mathrm{pH} 7.5,1 \mathrm{mM}$ NAD and $10 \mathrm{mM}$ dithiothreitol (DTT). The skin samples were first cut in a cryostat $(20-\mu \mathrm{m}$ sections) in order to enable homogenization of the stringy tissue. A glass homogenizer fitted with a teflon pestle was used. The homogenates were centrifuged at $110000 \mathrm{~g}$ for $60 \mathrm{~min}$ at $4^{\circ} \mathrm{C}$, the supernatant was stored in portions of $25 \mu \mathrm{l}$ at $-80^{\circ} \mathrm{C}$. These homogenates were used for the identification of the different ADH classes in the skin by comparison with the known isozyme patterns of hepatic and gastric rat tissue homogenates.

\section{Microdissection}

$10-\mu \mathrm{m}$ sections of unfixed skin were cut in a cryostat at a temperature of $-30^{\circ} \mathrm{C}$ and lyophilized under vacuum $\left(5 \times 10^{-3}\right.$ Torr $)$ at $-40^{\circ} \mathrm{C}$ for about $24 \mathrm{hr}$ [21]. After equilibration to room temperature, the freeze-dried sections were removed from the evacuation tubes and dissected free-hand with a self-made knife under a stereomicroscope in a room with controlled humidity $(20-30 \%)$ and temperature $\left(20^{\circ} \mathrm{C}\right)[21]$. For the recognition of structures in the lyophilized sections, parallel sections stained with hematoxylin/eosin were used. Samples of epidermis, sebaceous glands, hair roots, connective tissue and the panniculus carnosus were cut out of the lyophilized sections as shown in Fig. 1. Care was taken to ensure that the samples contained no trace of structures other than the one desired. The microdissected samples, weighing in the range of 50 to $300 \mathrm{ng}$ each as determined on a quartz fiber balance, were pooled to a total weight of $2 \pm 0.023 \mu \mathrm{g}$ for each structure examined.

\section{Extraction of alcohol dehydrogenase isozymes}

For the extraction, plastic caps of polypropylene tubes, serially arranged in brass holders and filled with $1 \mathrm{ml}$ paraffin oil, were used as containers. Under a stereomicroscope a $0.052 \mu \mathrm{l}$ droplet of extraction medium consisting of $20 \mathrm{mM}$ Tris-SO $\mathrm{SO}_{4}, \mathrm{pH} 7.5,1 \mathrm{mM}$ NAD, $10 \mathrm{mM}$ DTT and $1 \%$ Tween 20 was pipetted into each cap with a computer controlled micro-pipetting system [6] as described earlier [22]. The pooled tissue samples were then introduced through the oil into the medium and ADH isozymes were extracted by incubating the samples for $15 \mathrm{~min}$ at $20^{\circ} \mathrm{C}$.

\section{Preparation of glass plates for electrophoresis}

Glass plates measuring $10 \times 8.5 \times 0.5 \mathrm{~cm}$ were used. In order to form $100 \mu \mathrm{m}$ deep pockets in the gel layer for the application of samples, an alkali-treated polyester film was glued to a clean glass plate with araldite rapid. After the glue had hardened for $2 \mathrm{hr}$, the polyester film was planed to a thickness of $100 \mu \mathrm{m}$ using an object slide as a plane and metal bands as spacers. Rectangular segments measuring $6 \mathrm{~mm} \times 0.25 \mathrm{~mm}$ (for homogenate electrophoresis) and $1 \mathrm{~mm} \times 0.15 \mathrm{~mm}$ (for electrophoresis of microdissected samples) were cut out of the polyester film under a stereomicroscope. Excess polyester film and glue were removed. This cover plate was treated with repel silane in order to prevent the gel from adhering. Strips of $300 \mu \mathrm{m}$ thick adhesive tape were used as spacers along all four edges of the cover plate. The glass plate to which the gel was supposed to stick, was silanized with 3methacryloxy-propyltrimethoxysilane as formerly described [22] and stored at $4^{\circ} \mathrm{C}$.

\section{Preparation of $300 \mu \mathrm{m}$ gels}

7\% polyacrylamide gels (Long Ranger from FTC, USA), $300 \mu \mathrm{m}$ thick, were prepared. The polymerization solution, containing $10 \mathrm{mM}$ sodium phosphate buffer, 


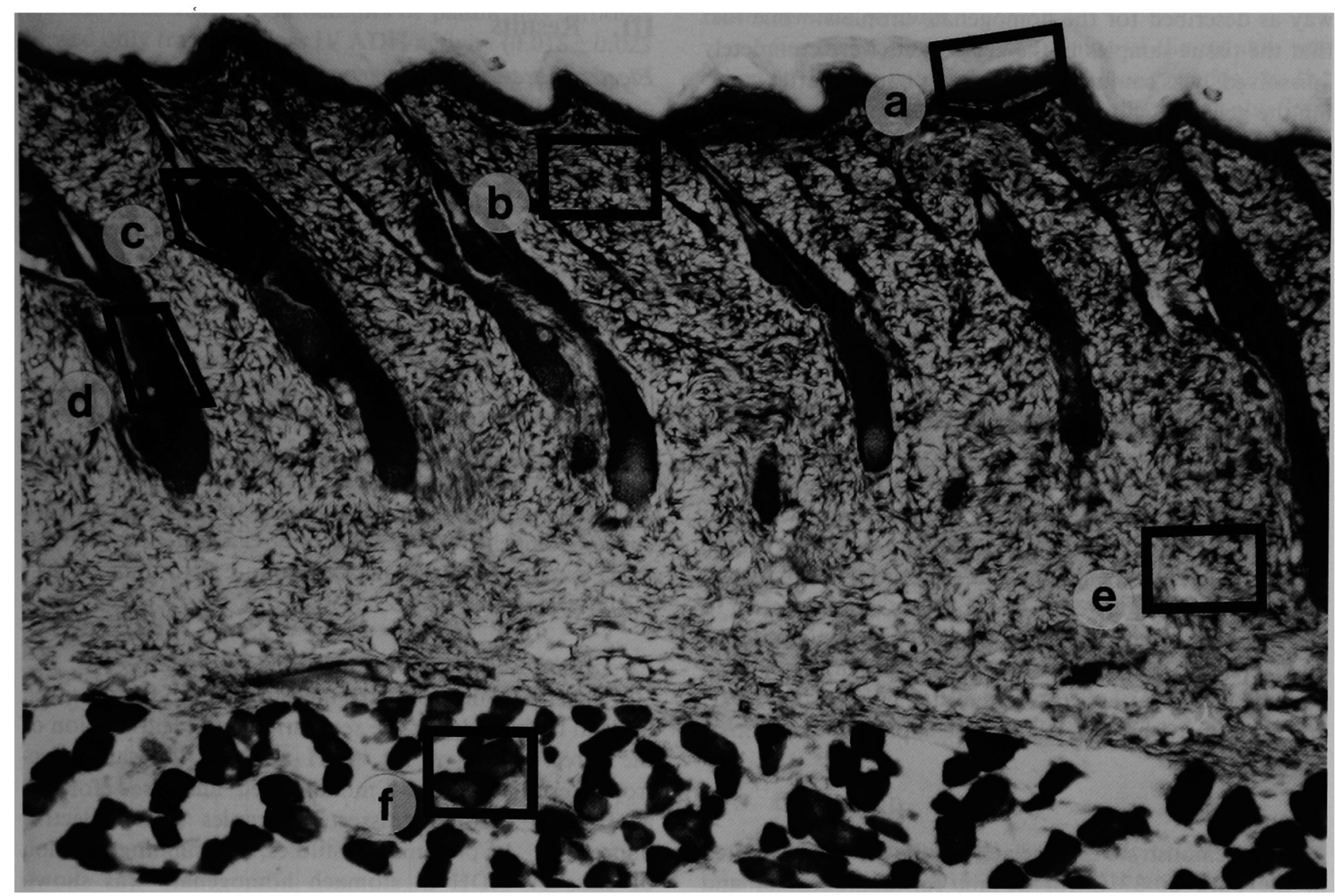

Fig. 1. Histochemical demonstration of ADH activity in the rat skin. Size and shape of the different microdissected skin samples are marked by black frames. a, epidermis; b, stratum papillare; c, sebaceous glands; $d$, hair root; e, stratum reticulare; f, panniculus carnosus. $\times 68$.

$\mathrm{pH} 7.0$ and an appropriate volume of Long Ranger solution, was degassed before use. Polymerization was achieved with $0.1 \%$ Temed and $0.05 \%$ ammonium persulfate. The gel was then cast by the so-called flap-technique [29]. After one hour of polymerization the cassette was opened and the gel washed three times for $15 \mathrm{~min}$ each in distilled water containing $0.5 \%$ Tween 20 in order to remove any impurities. The gel surface was then rinsed with distilled water and dried in a horizontal position at $40^{\circ} \mathrm{C}$ for 20 min under vacuum.

\section{Rehydration of the gel to $50 \%$ of its original thickness}

Gels that were not fully rehydrated [24] were used for electrophoresis. They were rehydrated with $50 \mathrm{mM}$ Tris$\mathrm{SO}_{4}, \mathrm{pH} 7.0,200 \mathrm{mM}$ ammonium sulfate, $1 \mathrm{mM}$ NAD and $0.3 \mathrm{mM}$ dithioerythritol. All the gels used were rehydrated to $150 \mu \mathrm{m}$ thickness ( $50 \%$ of the original volume) in a cooling chamber at $4{ }^{\circ} \mathrm{C}$. The cooled and degassed rehydration solution was pipetted onto one end of the rehydratation plate. The gel-bearing plate was then flapped onto the rehydration plate [24], trapping the rehydration solution and the gel in the rehydration chamber thus formed. Clamps were used to squeeze the plates. After
$20 \mathrm{~min}$ of reswelling at room-temperature the excess rehydration solution was sucked out of the cassette. The cassette was opened and the gel transferred to a tank with paraffin oil.

\section{Loading of samples}

A self made plastic pipette was used to load the samples into the gel pockets. For this an ordinary plastic capillary was stretched over a Bunsen burner. Under a stereomicroscope equipped with a $\mu \mathrm{m}$ scale the capillary was cut where its outer diameter measured about $200 \mu \mathrm{m}$. This capillary was then equipped with a mouthpiece.

$0.496 \mu \mathrm{l}$ of the liver, stomach or skin homogenate were pipetted under a stereomicroscope into a paraffin oil filled plastic cap, using a computer controlled micro-pipetting system. The whole of each homogenate droplet was transferred to the pockets in the gel by use of the abovementioned pipettes. The droplet was sucked up with this pipette from the cap together with a surrounding layer of paraffin oil. Under the stereomicroscope the droplets were pipetted into the oil-covered sample pockets.

The droplets containing the microdissected tissue samples were transferred to the sample pockets in the same 
way as described for the homogenate droplets. The fact that the tissue samples in the gel pockets were completely "dissolved" was confirmed by the clear banding after staining the gel.

\section{Separation}

Electrophoresis was carried out in a horizontal electrophoresis cell (Bio-Rad) equipped with a computer-controlled power supply (Bio-Rad; model 3000xi). 25 layers of filter paper served as an electrode buffer reservoir. The anode buffer contained $250 \mathrm{mM}$ Tris- $\mathrm{SO}_{4}, \mathrm{pH} 7.0,1 \mathrm{M}$ ammonium sulfate and $10 \mathrm{mM}$ Titriplex II, the cathode buffer contained $250 \mathrm{mM}$ Tris- $\mathrm{SO}_{4}, \mathrm{pH} 7.0,1 \mathrm{M}$ ammonium sulfate and $5 \mathrm{mM}$ NAD. Two layers of filter paper were arranged in parallel on the well-dried cooling plate as electrode wicks. About $5 \mathrm{ml}$ of paraffin oil was pipetted between the electrode wicks. The gel plate was then removed from the oil tank and placed upside down on the cooling plate, always making sure that the gel borders had good contact with the electrode wicks. Care was taken to ensure that the gap between gel and cooling plate was completely filled with paraffin oil, thus providing optimal cooling. The gel was run at constant conditions $\left(4^{\circ} \mathrm{C}\right.$, $26 \mathrm{~V} / \mathrm{cm}$ ) for $1.5 \mathrm{hr}$ (microdissected samples) or $3 \mathrm{hr}$ (homogenates).

\section{Staining}

To demonstrate enzyme activity the gel was incubated in the dark at $37^{\circ} \mathrm{C}$ for $20 \mathrm{~min}$ for homogenates and $60 \mathrm{~min}$ for microdissected tissue samples in the following medium: $100 \mathrm{mM}$ Tris- $\mathrm{HCl}, \mathrm{pH} 7.5,15 \%$ PVA, $10 \mathrm{mM}$ pyruvate, $2.5 \mathrm{mM}$ NAD, $1.5 \mathrm{mM}$ nitro-blue-tetrazoliumchloride, $0.326 \mathrm{mM}$ phenazine methosulfate, $50 \mathrm{mM}$ ethanol and $100 \mathrm{mM}$ crotyl alcohol. Staining was stopped by rinsing the gel in a $7.5 \%$ acetic acid solution for $15 \mathrm{~min}$ in the dark. After a final rinsing in distilled water the gel was dried at $45^{\circ} \mathrm{C}$. Bands of $\mathrm{ADH}$ were evaluated by densitometry (video densitometer Bio-Rad model 620 with a $600 \mathrm{~nm}$ interference filter and a high resolution lens) by manual peak integration (Integrated Area=I.A.).

\section{Histochemistry}

$10-\mu \mathrm{m}$ sections of unfixed rat skin embedded in tissue freezing medium were cut in a cryostat, thawed on cover slips and dried for $5 \mathrm{~min}$ at room temperature. They were immersed for another $5 \mathrm{~min}$ in ice cold acetone. After drying for $5 \mathrm{~min}$ at $37^{\circ} \mathrm{C}$, the sections were incubated for $20 \mathrm{~min}$ in the following medium: $300 \mathrm{mM}$ Tris- $\mathrm{HCl}$, pH 7.4, 20\% polyvinyl alcohol, $5 \mathrm{mM}$ nitro-blue-tetrazolium-chloride, $2 \mathrm{mM}$ NAD, $25 \mathrm{mM}$ crotyl alcohol, $5 \mathrm{mM}$ amytal, $0.3 \mathrm{mM}$ phenazine methosulfate and $10 \mathrm{mM} \mathrm{NaN}_{3}$. After incubation the sections were rinsed in $0.9 \% \mathrm{NaCl}$ and post-treated in a Ca-PVP-formalin solution for $20 \mathrm{~min}$ at $0^{\circ} \mathrm{C}$. They were then washed twice in distilled water for $5 \mathrm{~min}$ and embedded in Kaiser's glycerol gelatin.

\section{Results}

\section{Electrophoresis of homogenates}

In order to identify the different classes of ADH (for nomenclature see [13]), homogenates of liver as the main source of class I ADH [15], of stomach as a reference for class IV ADH [16] and of skin were electrophoretically separated. The analysis of these homogenates revealed three classes of ADH (Fig. 2). In the liver the more prominent, cathodically running band corresponded to class I ADH [15]. The weaker, slightly anodically migrating band represented the ubiquitous class III ADH [15]. The homogenate of stomach also showed a very faint band of class III ADH. Additionally, a very prominent band located anodically of class III ADH could be detected. This band represented class IV ADH $[15,16]$. The homogenate of skin showed the same electrophoretic pattern as the stomach homogenate; only class IV and to a far lesser extent class III ADH were found. No trace of class I ADH was detected.

\section{Electrophoresis of the microdissected samples}

After the "macroelectrophoretic" method had proved itself to be suitable for the separation and identification of the three classes of rat ADH activity, the same electrophoresis system was miniaturized and used for the analysis of the microdissected samples ("microelectrophoresis"). In preliminary studies, the staining reaction of class IV ADH in stomach homogenate was shown to be linear with weights within the range of $0.5 \mu \mathrm{g}$ and $1.25 \mu \mathrm{g}$ tissue (wet weight) per pocket after $60 \mathrm{~min}$ staining time.

Parallel to the microdissected samples of the skin, homogenates of liver and stomach were run on the same gel as references (Fig. 3). The microdissected samples of the skin showed variable activity of class IV ADH (Fig. 4 and Table 1). Among the epithelial structures, the epidermis and the sebaceous glands showed the highest activity of class IV ADH $(0.348 \pm 0.14$ I.A. and $0.324 \pm 0.104$ I.A., respectively) in contrast to the hair roots, which exhibited only $0.025 \pm 0.043 \mathrm{I}$.A. The connective tissue from the corium showed also class IV ADH activity. There, the highest ADH activity was located in the stratum papillare $(0.219 \pm 0.154$ I.A.) whereas the stratum reticulare accounted only for an inferior amount of ADH activity

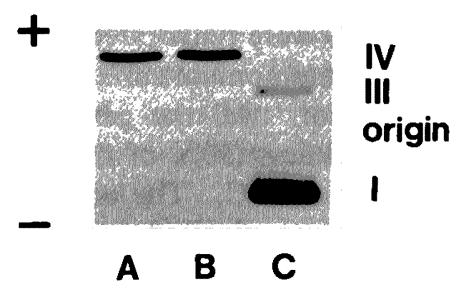

Fig. 2. Electrophoretic separation of ADH in homogenates of skin (A), stomach (B) and liver (C). Class I-(I), III-(III) and IV-(IV) ADH could be identified. 
$(0.042 \pm 0.038$ I.A.). The samples of panniculus carnosus showed only traces of class IV ADH activity $(0.018 \pm 0.023$ I.A.). Class I ADH activity was never detected in any of the microdissected samples.

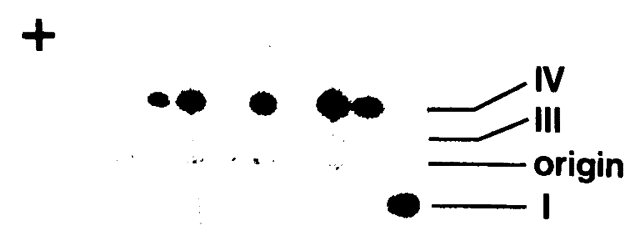

\section{ABCDE FGH}

Fig. 3. Microelectrophoretic separation of class I-(I), III-(III) and IV-(IV) ADH in microdissected samples of rat skin. Homogenates of stomach and liver were run on the same gel as references. A, panniculus carnosus; $B$, stratum reticulare; $C$, stratum papillare; D, hair roots; E, sebaceous glands; F, epidermis; G, stomach; H, liver.

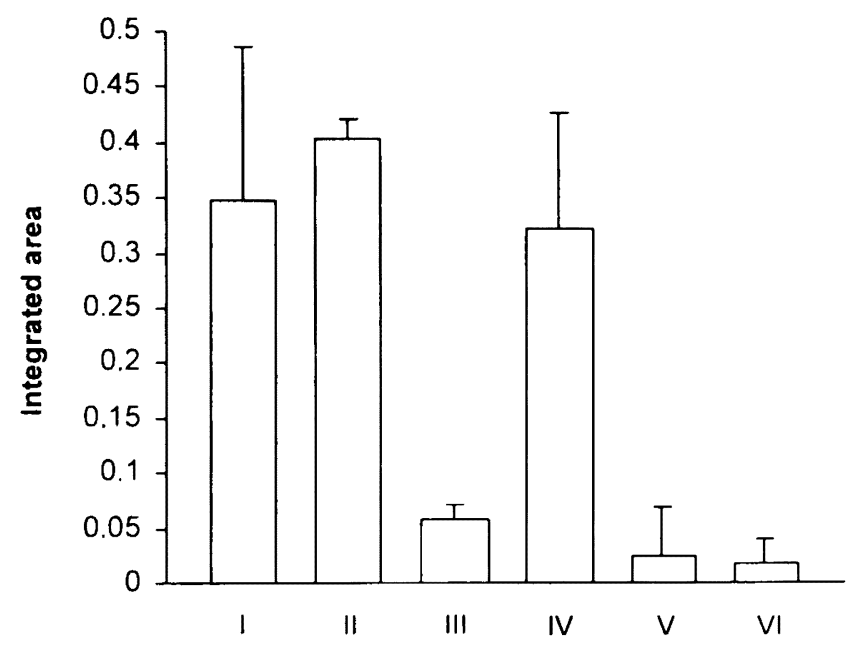

Fig. 4. Relative class IV ADH activity per $2 \mu \mathrm{g}$ dry weight of various structures of rat skin. I, epidermis; II, stratum papillare; III, stratum reticulare; IV, sebaceous glands; V, hair roots; VI, panniculus carnosus. Mean values and standard deviations were calculated from three animals $(n=3)$.

Table 1. Relative class IV ADH activity per $2 \mu \mathrm{g}$ dry weight of various structures of the skin.

\begin{tabular}{l|c}
\hline \multicolumn{2}{c}{ class IV ADH activity per $2 \mu \mathrm{g}$ tissue dry weight } \\
\hline epidermis & $0.348 \pm 0.140 \mathrm{I}$. A. \\
\hline stratum papillare & $0.405 \pm 0.018 \mathrm{I}$. A. \\
\hline stratum reticulare & $0.057 \pm 0.015 \mathrm{I}$. A. \\
\hline sebaceous glands & $0.324 \pm 0.104 \mathrm{I} . \mathrm{A}$. \\
\hline hair roots & $0.025 \pm 0.043 \mathrm{I} . \mathrm{A}$. \\
\hline panniculus carnosus & $0.018 \pm 0.023 \mathrm{I} . \mathrm{A}$. \\
\hline
\end{tabular}

Mean values and standard deviations were calculated from three animals $(n=3)$.

\section{Histochemical findings}

After incubation, intense staining of the rat skin was observed in the epidermis, in sebaceous glands, in the stratum papillare of the dermis, in the panniculus carnosus, and in parts of the hair root. In the epidermis, maximum activity was present in the basal layers (Fig. 5B). Enzyme activity decreased towards the surface and disappeared in the stratum granulosum. The stratum corneum showed no activity at all. In the sebaceous glands, maximum activity was located in the marginal cells, although the central cells also exhibited high activity (Fig. 5A). The fibrocytes/fibroblasts of the corial connective tissue reacted very intensely, making evident the reticular pattern of the cellular processes (Fig. 5C, D). Most intense reactivity was seen in the region of the stratum papillare. The hair roots exhibited extremely high activity right above the hair follicle (Fig. 5E). The striated muscle of the panniculus carnosus also showed a moderate reaction (Fig. 5F).

The staining reaction could not be inhibited completely by using 4-methylpyrazole up to a concentration of $100 \mathrm{mM}$ in the incubation medium. Neither omission of NAD nor addition of $10 \mathrm{mM}$ pyruvate to the medium were able to inhibit the reaction completely.

\section{Discussion}

The patterns obtained by the microelectrophoretic separation of the ADH classes I, III and IV in liver, stomach and skin homogenates matched the patterns obtained after conventional starch gel electrophoresis described in the literature $[1,15]$ and therefore allowed the precise identification of the three different classes of ADH. The occurrence of class I and III ADH in the homogenate of liver and of class III and IV ADH in the homogenates of stomach and skin are in agreement with the findings of other authors $[1,15]$.

In contrast to the unequivocal results of the electrophoretic analysis the histochemical data require more critical interpretation. In general the staining intensity reflected the $\mathrm{ADH}$ activity which was measured after the microelectrophoretic procedure very well. But since the histochemical reaction could not be completely inhibited by the omission of substrate or coenzyme, or by the addition of 4-methylpyrazole or pyruvate to the incubation medium, the remaining "background" activity must be attibuted to a false positive reaction, mainly to the so-called "nothing-dehydrogenase". This activity is considered to be the result of lactate dehydrogenase oxidizing endogenous lactate, as well as to thiol groups exerting a reducing effect on the tetrazolium salt [30]. Since $60 \mathrm{mM}$ pyruvate in the incubation medium should lead to a complete inhibition of lactate dehydrogenase [32], the remaining non-specific staining must mainly be accounted for by the reducing thiol groups such as glutathione or cysteine present in tissue proteins. This assumption is supported by our findings of high histochemical activity in hair roots 

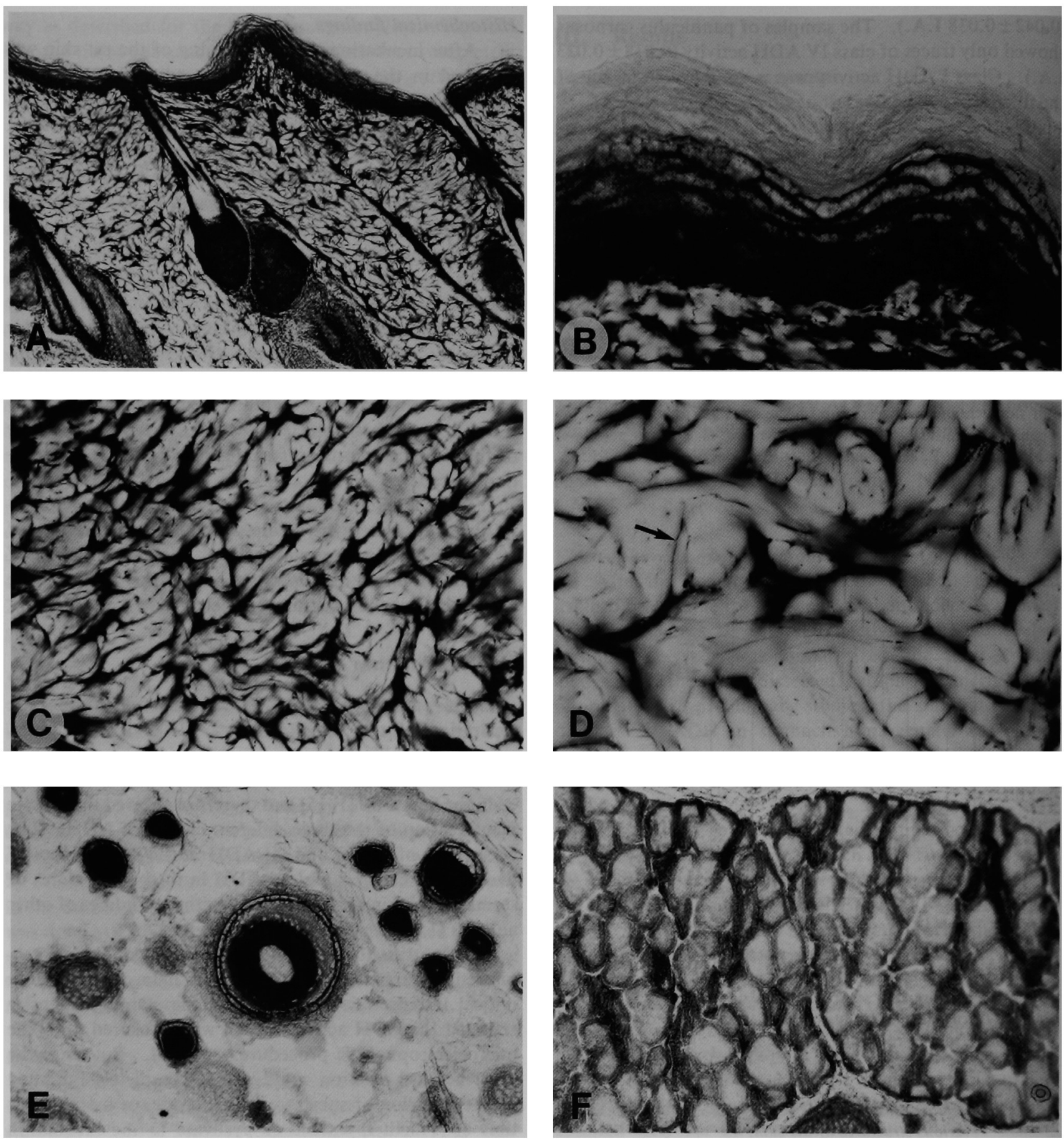

Fig. 5. Histochemical demonstration of ADH activity in various structures of rat skin. A: sebaceous glands, B: epidermis, C: reticular pattern of the dermal fibroblasts, $\mathbf{D}$ : delicate processes of the fibroblasts became apparent by the enzyme reaction (arrow), E: cross-sections of hair roots right above the hair follicle, F: panniculus carnosus. Magnification: A $\times 104, \mathbf{B} \times 416, \mathbf{C} \times 332, \mathbf{D} \times 532, \mathbf{E} \times 133, \mathbf{F} \times 133$.

(a cysteine-rich structure), which is in contrast to the mere traces of ADH activity found by the microelectrophoretic analysis. Moreover, the intense staining still observed after electrophoresis in the hair root samples cannot originate from the activity of the soluble ADH which would have migrated into the gel, but must be caused by non-extractable proteins containing thiol-groups.
Also the ADH activity which was histochemically demonstrated in the panniculus carnosus can only partly be correlated with the rather moderate $\mathrm{ADH}$ values in the microdissected samples. Thus the histochemical ADH activity of this muscle layer also has to be regarded with caution.

The ADH activity of the connective tissue could be 
demonstrated by both the histochemical method as well as by microdissection to decrease from the stratum papillare to the stratum reticulare. This can be explained at least in part by the differences in cell density between the high cellular and low extracellular matrix content of the stratum papillare and the lower cellular and higher extracellular matrix content of the stratum reticulare. Since $\mathrm{ADH}$ is a cytosolic marker enzyme, the formazan deposits demonstrated histochemically the pronounced reticular pattern of the cellular processes of fibroblasts/fibrocytes in the connective tissue of the skin. Due to the inhomogeneity of the tissue samples examined, the quantitative determination of ADH class IV activity per dry weight of the different skin structures revealed rather high standard deviation errors. Thus quantitative interpretation has to be cautious.

Together our results endorse the fact that class III and IV $\mathrm{ADH}$ are the only $\mathrm{ADH}$ classes detectable in the rat skin.

Other authors have shown class IV ADH to be present in adult mouse skin by immunohistochemistry, by northern/southern blot techniques and by in situ hybridization [10, 34]. Although class I ADH has also been detected in fetal mouse skin [31], it was shown to be absent from the skin of adult mice [10], which is in agreement with our findings in the adult rat. In mouse epidermis, class IV ADH activity was located primarily in the basal cell layers [10]. This distribution pattern is corroborated by our similar findings in the rat.

From in situ hybridization techniques it could not be concluded if class I and IV ADH were expressed in mouse skin fibroblasts [10]. However, immunohistochemical investigations by the same authors showed class IV ADH in dermal mouse fibroblasts. The electrophoretic results presented here clearly reveal that high activity of class IV ADH also occurs in rat skin fibroblasts.

Since the stratum papillare exhibited about the same activity of class IV ADH per $\mathrm{g}$ dry weight tissue as the epidermis, a further consideration must be taken into account: Morphometric measurements (not mentioned in the results) point to a cellular portion of about $25 \%$ of the total connective tissue volume. With respect to the only intracellular location of $\mathrm{ADH}$, the enzyme activity of the fibroblasts has to be multiplied by a factor of four. Consequently, a defined cytosolic volume of fibroblasts would have a higher capacity to metabolize class IV $\mathrm{ADH}$ substrates than any comparable cytoplasmic volume of all other cell types examined in the rat skin.

The presence of high activity of class IV ADH in the epidermis, sebaceous glands and, above all, in the connective tissue raises the question of its physiological metabolic role.

Class IV ADH has been considered responsible for a firstpass metabolism of ingested ethanol in the upper digestive tract, where $1 \mathrm{M}$ ethanol concentrations can be reached [16]; however, the blood ethanol concentrations reaching the skin after oral ingestion are far too low (in general below $50 \mathrm{mM}$ ) to saturate the enzyme, which has a $\mathrm{K}_{m}$ of $5000 \mathrm{mM}$ [1]. Thus class IV ADH in the skin can be expected to be insignificant with regard to detoxification of ingested ethanol. Furthermore, class IV ADH is considered to be involved in retinoic acid synthesis [2, 3, 33], in the reduction of cytotoxic aldehydes from lipid peroxidation [2] and in the $\omega$-oxidation of hydroxyfatty acids [2], a pathway that has been detected in prostaglandin and leukotriene inactivation. Two of these functions are of direct importance for the skin: retinoic acid synthesis and the reduction of lipid peroxidation products.

The biosynthesis of retinoic acid includes two oxidative steps. Retinol is converted to the biologically more potent metabolite retinoic acid via retinal [17]. The first oxidative step can be catalyzed by cytosolic ADH. In vitro $\mathrm{ADH}$ class I and IV are able to oxidize retinol to retinal [2, 16], class IV showing lower affinity towards retinol than class I ADH. The ubiquitous class III ADH is inactive towards retinol [2]. Therefore in the rat skin, class IV ADH is an important candidate for retinol oxidation.

It becomes more and more evident that retinoic acid plays a role in epithelial differentiation $[7,27]$. The role of class IV ADH in the basal epithelial cell layers and fibroblasts of the adjacent stratum papillare in regard to retinoic acid synthesis and epithelial differentiation remains to be clarified.

Class IV ADH has further been assumed to participate in the elimination of cytotoxic aldehydes generated by lipid peroxidation of membrane lipids. In vitro, it is active towards substrates such as 4-hydroxynonenal, 2-hexenal and hexanal [2]. Lipid peroxidation can be initialized by free radicals like the hydroxyl radical, which can be generated in the skin by environmental agents such as air pollutants and solar radiation [4] or endogenous metabolic processes [28]. The lipid peroxidation product 4-hydroxynonenal, for example, has cytotoxic, hepatotoxic, mutagenic and genotoxic properties [5]. Considering this toxicity the skin should have a potent detoxification system.

Despite the data presented here on the topochemical differences of class IV ADH in various structures of the rat skin, the enzyme's physiological functions remain hypothetical for the present. It has to be clarified whether class IV ADH really participates in the retinoid metabolism and/or the catabolism of lipid peroxidation products, or whether it is involved in still unknown metabolic functions.

\section{Acknowledgments}

We thank Dr. F. Steel for helping us with the English text.

\section{References}

1. Boleda, M. D., Julià, P., Moreno, A. and Parés, X.: Role of 
extrahepatic alcohol dehydrogenase in rat ethanol metabolism. Arch. Biochem. Biophys. 274; 74-81, 1989.

2. Boleda, M. D., Saubi, N., Farrés, J. and Parés, X.: Physiological substrates for rat alcohol dehydrogenase classes: aldehydes of lipid peroxidation, $\omega$-hydroxyfatty acids, and retinoids. Arch. Biochem. Biophys. 307; 85-95, 1993.

3. Duester, G.: Involvement of alcohol dehydrogenase, shortchain dehydrogenase/reductase, aldehyde dehydrogenase, and cytochrome $\mathrm{P} 450$ in the control of retinoid signaling by activation of retinoic acid synthesis. Biochemistry 35; 12221-12227, 1996.

4. Emerit, I.: Free radicals and aging of the skin. In "Free Radicals and Aging", ed. by I. Emerit and B. Chance, Birkhäuser Verlag, Basel Boston Berlin, 1992, pp. 328-341.

5. Esterbauer, H., Zollner, H. and Schaur, R. J.: Hydroxyalkenals: cytotoxic products of lipid peroxidation. ISI Atlas Sci. Biochem. 1; 311-317, 1988.

6. Fink, H. and Pette, D.: An automated micropipet especially designed for use with the oil-well technique. Anal. Biochem. 133; 220-225, 1983.

7. Fuchs, E.: Epidermal differentiation: the bare essentials. $J$. Cell Biol. 111; 2807-2814, 1990.

8. Goslar, H. G.: Beiträge zum Häutungsvorgang der Schlangen. 2. Mitteilung. Acta Histochem. 17; 1-60, 1964.

9. Handschin, R.: Activity of different classes of alcohol dehydrogenases in structures of rat skin. A microquantitative analysis. Inaug.-Diss. Med. Fak., Univ. Basel, Switzerland, 1997.

10. Haselbeck, R. J., Ang, H. L. and Duester, G.: Class IV alcohol/retinol dehydrogenase localization in epidermal basal layer: potential site of retinoic acid synthesis during skin development. Dev. Dyn. 208; 447-453, 1997.

11. Holmes, R. S.: Alcohol dehydrogenases: a family of isozymes with differential functions. Alcohol. Alcohol. Suppl 2; 127-130, 1994.

12. Iborra, F. J., Renau-Piqueras, J., Portoles, M., Boleda, M. D., Guerri, C. and Parés, X.: Immunocytochemical and biochemical demonstration of formaldehyde dehydrogenase (class III alcohol dehydrogenase) in the nucleus. J. Histochem. Cytochem. 40; 1865-1878, 1992.

13. Jörnvall, H. and Höög, J. -O.: Nomenclature of alcohol dehydrogenases. Alcohol. Alcohol. 30; 153-161, 1995.

14. Jörnvall, H., Danielsson, O., Hijelmqvist, L., Persson, B. and Shafqat, J.: The alcohol dehydrogenase system. Adv. Exp. Med. Biol. 372; 281-294, 1995.

15. Julià, P., Farrés, J. and Parés, X.: Characterization of three isoenzymes of rat alcohol dehydrogenase. Tissue distribution and physical and enzymatic properties. Eur. J. Biochem. 162; 179-189, 1987a.

16. Julià, P., Boleda, M. D. and Parés, X.: Kinetic properties and physiological significance of the ADH-1 isoenzyme of rat stomach alcohol dehydrogenase. Prog. Clin. Biol. Res. 232; 189-201, 1987b.

17. Kim, C. -I., Leo, M. A. and Lieber, C. S.: Retinol forms retinoic acid via retinal. Arch. Biochem. Biophys. 294; 388-393, 1992.

18. Koivusalo, M., Baumann, M. and Uotila, L.: Evidence for the identity of glutathione-dependent formaldehyde dehydrogenase and class III alcohol dehydrogenase. FEBS Lett. 257; 105-109,
1989.

19. Krieger, K., Maly, I. P., Toranelli, M., Crotet, V. and Sasse, D.: Ultrathin-layer microelectrophoretic determination of lactate dehydrogenase isoenzymes in corneal and conjunctival epithelium of the cow. Histochemistry 101; 271-275, 1994.

20. Lad, P. J. and Leffert, H. L.: Rat liver alcohol dehydrogenase. I. Purification and characterization. Anal. Biochem. 133; 350-361, 1983.

21. Lowry, O.H. and Passonneau, J. V.: A flexible system of enzymatic analysis, Academic Press, New York San Francisco London, 1972, pp. 223-249.

22. Maly, I. P. and Toranelli, M.: Ultrathin-layer zone electrophoresis of lactate dehydrogenase isoenzymes in microdissected liver samples. Anal. Biochem. 214; 379-388, 1993.

23. Maly, I. P., Toranelli, M. and Sasse, D.: Intra-acinar profiles of cytosolic and mitochondrial malate dehydrogenase isoenzymes in rat liver. J. Histochem. Cytochem. 42; 855-859, 1994.

24. Maly, I. P., Toranelli, M., Crotet, V. and Sasse, D.: Ultrathinlayer zone electrophoresis of alcohol dehydrogenase in polyacrylamid gels. An alternative to starch gel electrophoresis. (in press)

25. Mezey, E. and Potter, J. J.: Separation and partial characterization of multiple forms of rat liver alcohol dehydrogenase. Arch. Biochem. Biophys. 225; 787-794, 1983.

26. Montagna, W. and Ellis, R. A.: Histochemistry of enzymes in the skin. In "Handbuch der Histochemie" vol. 7(2), ed. by W. Graumann and K. Neumann, Gustav Fischer Verlag, Stuttgart, 1962.

27. Peck, G. L. and DiGiovanna, J. J.: Synthetic retinoids in dermatology. In "The Retinoids. Biology, Chemistry and Medicine", 2nd ed., ed. by M. B. Sporn, A. B. Roberts and D. S. Goodman, Raven Press, Ltd., New York, 1994, pp. 631-658.

28. Punchard, N. A. and Kelly, F. J.: Free radicals. A practical approach, Oxford University Press, Oxford, 1996, pp. 1-8.

29. Radola, B. J.: Ultrathin-layer isoelectric focussing 50-100 $\mu \mathrm{m}$ polyacrylamide gels on silanized glass plates or polyester films. Electrophoresis 1; 43-56, 1980.

30. Stoward, P. J., Altman, F. P. and Seidler, E.: Principles of oxidoreductase histochemistry. In "Histochemistry. Theoretical and Applied", vol. 3, Enzyme Histochemistry, 4th ed., ed. by P. J. Stoward and A. G. E. Pearse, Churchill Livingstone, London, 1991, pp. 1-25.

31. Tietjen, T. G., Mjaatvedt, C. H. and Yang, V. W.: Expression of class IV alcohol dehydrogenase gene in developping rat fetuses. J. Histochem. Cytochem. 42; 745-753, 1994.

32. Van Noorden, C. J., Kooij, A., Vogels, I. M. and Frederiks, W. M.: On the nature of the 'nothing dehydrogenase' reaction. Histochem. J. 17; 1111-1118, 1985.

33. Yang, Z. -N., Davis, G. J., Hurley, T. D., Stone, C. L., Li, T. -K. and Bosron, W.F.: Catalytic efficiency of human alcohol dehydrogenases for retinol oxidation and retinal reduction. Alcohol. Clin. Exp. Res. 18; 587-591, 1994.

34. Zgombic-Knight, M., Ang, H. L., Foglio, M. H. and Duester, G.: Cloning of the mouse class IV alcohol dehydrogenase (retinol dehydrogenase) cDNA and tissue-specific expression patterns of the murine ADH gene family. J. Biol. Chem. 270; 10868-10877, 1995. 